\title{
Uma análise empírica da padronização de frota de companhias aéreas e os efeitos de fatores operacionais
}

\author{
Rodolfo Romboli Narcizo ${ }^{1}$, Alessandro V. M. Oliveira ${ }^{2}$ \\ 1Programa de Engenharia de Infraestrutura Aeronáutica, Instituto Tecnológico de Aeronáutica, rrn93@hotmail.com \\ ${ }^{2}$ Programa de Engenharia de Infraestrutura Aeronáutica, Instituto Tecnológico de Aeronáutica, alessandro@ita.br
}

\section{Recebido: \\ 15 de fevereiro de 2018 \\ Aceito para publicação: \\ 13 de maio de 2018 \\ Publicado: \\ 4 de novembro 2018 \\ Editor de área: \\ Cira Pitombo, EESC-USP}

\section{Palavras-chaves:}

Gerenciamento de frota;

Custos com combustível;

Inovação tecnológica;

Estratégia empresarial;

Política ambiental.

\section{Keywords:}

Fleet management;

Fuel costs;

Technological innovation;

Business strategy;

Environmental policy.

DOI:10.14295/transportes.v26i3.1587

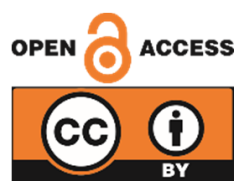

\begin{abstract}
RESUMO
O presente trabalho desenvolve um modelo econométrico para avaliar alguns dos fatores determinantes das estratégias de padronização de frota de companhias aéreas. Considera-se a padronização em nível de modelo de aeronave, com controles dos efeitos da padronização de fabricante e de família dos equipamentos de voo. O modelo empírico foi estimado com dados do transporte aéreo brasileiro e utiliza diversas variáveis operacionais, como tamanho e idade médios da frota, fluxo de passageiros por voo e número de destinos servidos. $O$ efeito de fatores de custos operacionais e de demanda são também incorporados ao modelo. Os resultados apontam para uma tendência à maior padronização de frota no Brasil. Entretanto, aumentos nos custos com combustível podem atenuar essa tendência, por induzir uma busca por aeronaves com tecnologia mais avançada e menor consumo energético. Os resultados da pesquisa possuem implicações de políticas corporativas e públicas visando ao estímulo da gestão eficiente e sustentável da frota das companhias aéreas no país ao longo dos próximos anos.
\end{abstract}

\section{ABSTRACT}

This paper develops an econometric model to assess some of the determining factors of the fleet standardization strategies of airlines. Standardization is considered at the aircraft model level, after controlling for the effects of manufacturer and family standardization of flight equipment. The empirical model was estimated using Brazilian air transportation data and utilizes several operational variables, such as average aircraft size and fleet age, passenger flow per flight and number of served destinations. The effect of operating costs and demand factors are also incorporated into the model. The results point to a tendency towards greater standardization of the fleet in Brazil. However, increases in fuel costs may mitigate this trend by inducing a search for aircraft with more advanced technology and lower energy consumption. The research results have implications for corporate and public policies aimed at stimulating the efficient and sustainable management of the airline fleet in the country over the next few years.

\section{INTRODUÇÃO}

A padronização de frota no transporte aéreo é um fator geralmente associado à redução de custos operacionais e, em particular, às companhias aéreas voltadas ao modelo de negócio de baixo custo (low cost carriers). Entretanto, com o aumento da competitividade do setor após a desregulação econômica ocorrida em diversos países, a gestão da frota aérea com elementos dessa padronização, e de acordo com as condições de mercado, vem ganhando destaque.

A característica de padronização de frota é bastante presente em diversas companhias aéreas ao redor do mundo. Nos Estados Unidos, a Southwest Airlines, por exemplo, que possui uma frota inteiramente composta por aeronaves da família Boeing 737, reafirmou em 2011, a sua 
preferência pelas aeronaves daquele fabricante ao fazer um pedido de 350 aeronaves do novo modelo 737 MAX (FlightGlobal, 2011). A redução nos custos e a melhoria na eficiência das operações - fatores rotineiramente associados aos supostos benefícios decorrentes da padronização de frota - foram as razões apresentadas pelo chefe executivo de operações da companhia para a escolha daquele modelo, ao invés do também novo Airbus A320neo.

Infere-se, assim, que a análise da padronização de frota possui implicações não apenas quanto à competitividade de custos no setor de transporte aéreo, mas também à sustentabilidade das operações quanto à gestão e aquisição de aeronaves tecnologicamente mais avançadas e desejáveis do ponto de vista ambiental, no tocante a emissões e ruído aeronáuticos.

Tem-se observado ao longo das últimas décadas, que novos modelos de aeronaves têm sido lançados pelos fabricantes em intervalos de tempo relativamente curtos. Esse fator contribui para reduzir o prazo médio em que companhias aéreas de maior porte utilizam seus equipamentos de voo, antes de trocá-los por modelos mais novos e tecnologicamente mais avançados. Pode-se optar por novas aeronaves dos mesmos modelos operados pela empresa (maior padronização da frota), ou pode-se partir para a aquisição de novos modelos de aeronaves (menor padronização da frota). Constata-se, entretanto, que os fatores determinantes para essa decisão de padronizar ou não a frota pelas companhias aéreas, ainda são aspectos pouco abordados na literatura existente e com grande potencial científico.

Os estudos atuais da literatura têm como enfoque um efeito importante da padronização de frotas - o efeito da comunalidade de peças de reposição e tripulantes nos custos operacionais das empresas. Por outro lado, o questionamento das razões e incentivos pelas quais uma companhia aérea padronizaria sua frota ainda não foi profundamente abordado. Tem-se como objetivo desta pesquisa, portanto, preencher essa lacuna e compreender melhor quais os fatores que levam a uma operadora a padronizar sua frota em sua gestão das operações. Um modelo econométrico de determinantes da padronização da frota de companhias brasileiras, utilizando uma amostra com observações ao longo de mais de dez anos e para as quatro maiores empresas atualmente no mercado, foi desenvolvido com esse objetivo.

0 presente trabalho está assim dividido: Na Seção 2, é apresentada uma revisão da literatura na área; Na Seção 3, apresenta-se a metodologia, com discussão dos modelos conceitual e empírico; a Seção 4 apresenta os resultados do modelo; por fim, na Seção 5, são apresentadas as considerações finais.

\section{REVISÃO DE LITERATURA}

\subsection{Comunalidade de frota}

A ideia transmitida pelo termo "comunalidade" remete ao significado da palavra "comum". De forma geral, afirmar que uma frota contém um elevado índice de comunalidade seria o mesmo que afirmar que essa mesma frota possui diversos fatores em comum. 0 termo é frequentemente utilizado por fabricantes de aeronaves para indicar a quantidade de peças equivalentes e intercambiáveis entre os seus próprios modelos. Por essa razão, a comunalidade é geralmente associada a aeronaves que pertençam a uma mesma família, já que estas foram desenvolvidas sobre um mesmo projeto base e tendem a possuir maior compartilhamento de peças.

Cabe destacar uma ligeira diferença conceitual entre os termos comunalidade e padronização de frota. Enquanto o primeiro tende a indicar e quantificar as similaridades de peças e componentes entre duas ou mais aeronaves, o segundo termo remete mais apropriadamente à ideia 
de busca por um padrão único, o qual pode ser observado de diversas maneiras, dependendo do padrão o qual está sendo buscado.

Brüggen e Klose (2010) discutem que uma frota pode ser completamente padronizada, mas ainda assim pode não estar no mais elevado nível de comunalidade possível. Isso se deve ao fato de que a comunalidade está mais associada à tomada de decisão do fabricante da aeronave, enquanto que a padronização de frota está vinculada à tomada de decisão da companhia aérea. Observa-se, por exemplo, que uma frota pode ser inteiramente composta por aeronaves do modelo Airbus A320, o que representaria uma frota inteiramente padronizada em modelo de aeronave. Entretanto, uma vez que o fabricante da aeronave autoriza tanto o emprego de motores do tipo CFM56 quanto IAE V2500, essa mesma frota pode ter índices de comunalidade diversos dependendo de como foi motorizada.

A diferença entre os conceitos de comunalidade e padronização tem repercussões na literatura. Borges Pan e Espírito Santo (2004), por exemplo, segmentaram a comunalidade de acordo com partes da aeronave, como motor e célula. Isso significa que, considerando o Índice para Motor (IPM) criado pelos autores, uma frota com um elevado número de aeronaves com uma mesma motorização resultaria em um alto índice IPM. De maneira análoga, uma frota com fuselagens similares também teria resultados elevados quando considerando o Índice para Célula (IPC). A avaliação de frota como um todo se dá pelo Índice de Padronização de Frota (IPF), o qual é calculado através dos dois primeiros índices.

Já Zou, Yu e Dresner (2015) utilizam diretamente o conceito de padronização de frota. Os autores sugerem a segmentação da padronização por níveis de fabricante, família e modelo de aeronave. A ideia apresentada pelos autores remete ao Herfindahl-Hirshman Index (HHI), índice comumente usado para representação de concentração de mercado. Os resultados possíveis obtidos pelo método dos autores variam de 0 a 1 , sendo que quanto mais próximo de zero, menor é a padronização de frota. Este método de análise apresenta maior proximidade com o conceito puro de padronização de frota do que o índice IPF, o qual captura mais aspectos ligados à comunalidade.

Cabe destacar que as características idiossincráticas de cada aeronave na frota não são consideradas individualmente no método de Zou, Yu e Dresner (2015), mas, sim, apenas o modelo de aeronave em questão. Por se tratar de níveis, uma frota composta por aeronaves de um mesmo fabricante seria, naturalmente, possuidora de elevada padronização por fabricante, porém não necessariamente também teria um índice elevado em nível de família e modelo. Entretanto, há de se notar que um elevado índice por modelo implica também em alta padronização de família e fabricante, uma vez que cada modelo de aeronave pertence obrigatoriamente a uma família, e essa, por sua vez, faz parte do conjunto de aeronaves produzidas por um fabricante.

A métrica utilizada na presente pesquisa para o cálculo da padronização foi a desenvolvida por Zou, Yu e Dresner (2015), sendo exemplificada pelo cálculo apresentado na Tabela 1. Na tabela, são apresentados os índices HHI de modelo, família e fabricante das quatro maiores companhias aéreas brasileiras, sendo evidenciados os modelos utilizados por cada uma delas e suas respectivas quantidades.

Ressalta-se que, embora os índices HHI desenvolvidos pelos autores funcione de forma mais apropriada para observar a padronização do que a comunalidade em si, eles são utilizados no presente trabalho como uma alternativa para a estimação da comunalidade existente em uma frota. A ideia para isso baseia-se na impraticabilidade de se identificar todos os aspectos que 
podem ser divergentes em uma frota, fazendo com que o índice de padronização funcione como uma variável proxy e seja uma forma eficiente de estimar a comunalidade existente.

Tabela 1: Padronização de frota das companhias brasileiras regulares em dezembro de 2016

\begin{tabular}{llllll}
\hline Companhia Aérea & Modelos de aeronaves na frota & Tamanho da Frota & HHI Modelo & HHI Família & HHI Fabricante \\
\hline Avianca & 10 A318; 4 A319; & 47 & 0.489 & 0.919 & 1.000 \\
& 31 A320; 2 A332 & & & & 0.381 \\
\hline Azul & 5 A320; 5 A332; 39 ATR72; & 123 & 0.466 & \\
& 10 E190; 64 E195 & & 0.642 & 1.000 & 1.000 \\
\hline Gol & 28 B737; 92 B738 & 120 & 0.276 & 0.649 & 0.727 \\
\hline Latam & 21 A319; 65 A320; 31 A321; & 147 & & & \\
\hline Tabela elaborada a partir de informações do Panorama 2016 da ABEAR (ABEAR, 2017). & &
\end{tabular}

\subsection{Efeitos da comunalidade}

O efeito da comunalidade nos custos operacionais das companhias aéreas já percorreu diversos artigos. De maneira geral, os trabalhos buscam identificar os efeitos da comunalidade nos custos operacionais totais, os quais englobam gastos com combustível, manutenção, tripulação, arrendamento, entre outros. A comunalidade é costumeiramente associada à redução de custos e a companhias low-cost, justamente devido ao seu modelo de negócio de baixo custo (Kilpi, 2007; Brüggen e Klose, 2010; Zuidberg, 2014; Zou, Yu e Dresner, 2015).

Seristö e Vepsälainen (1997) sugerem uma correlação negativa entre comunalidade de frota e custos com operações de voo e manutenção de aeronave. Os autores também ressaltam que o coeficiente dos custos de manutenção apresentou-se muito próximo de zero, o que seria um indicativo de que a real economia gerada pela comunalidade seria decorrente dos gastos com operações de voo. Zuidberg (2014) também obteve resultados indicativos de uma correlação negativa entre custos operacionais e comunalidade de frota, porém sem que apresentassem significância estatística. Brüggen e Klose (2010) indicam que o desempenho operacional de uma companhia aérea é positivamente associado a uma frota única e que essa relação é intensificada conforme ocorre um aumento em seu tamanho, uma vez que isso otimizaria os trabalhos técnicos na companhia e traria um ganho de escala.

Kilpi (2007) sugere que companhias com frotas menos diversificadas teriam a tendência de obter melhores resultados financeiros, justamente devido a uma alta correlação entre uniformidade e lucro operacional. Note que o autor não explica se o aumento no lucro é resultado de uma redução nos custos operacionais ou é devido a um aumento na receita.

A falta de explicação de resultados observados no artigo de Kilpi (2007) apresenta-se de maneira relevante quando comparados com os resultados de Zou, Yu e Dresner (2015). Esses autores afirmam que a padronização de frota teria um efeito negativo sobre a margem de lucro, uma vez que essa característica limitaria a capacidade da companhia de responder rapidamente a uma variação na demanda ou a ações de competidores. Note que os autores também encontraram indícios de redução de custos em frotas padronizadas em nível de modelo ou de família. Tais resultados são, portanto, indícios de que a presença de frota única poderia, além de diminuir os custos operacionais, reduzir também a receita auferida. 


\section{METODOLOGIA}

\subsection{Modelo conceitual e empírico}

A presente pesquisa utiliza-se de um modelo econométrico para estudar os possíveis fatores determinantes da decisão de padronização de frota das companhias aéreas. Em particular, o modelo empírico investiga a influência de aspectos operacionais e de fatores de mercado. Por meio da modelagem, torna-se possível a verificação do impacto isolado de cada variável - o chamado efeito ceteris paribus -, como por exemplo, o impacto da presença de padronização em outros níveis, da idade e tamanho da frota, entre outros. As variáveis utilizadas no modelo podem ser visualizadas no modelo empírico representado na Equação (1).

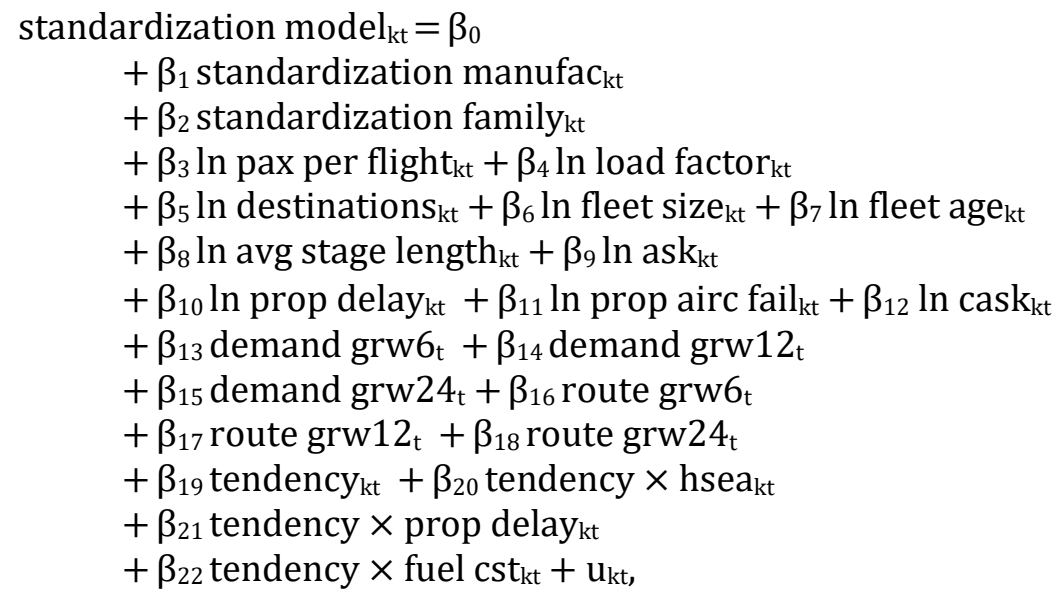

em que:

standardization modelkt: representação do índice de comunalidade criado por Zou, Yu e Dresner (2015) em nível de modelo de aeronave;

standardization manufackt: representação do índice de comunalidade criado por Zou, Yu e Dresner (2015) em nível de fabricante de aeronave;

standardization familykt: representação do índice de comunalidade criado por Zou, Yu e Dresner (2015) em nível de família de aeronave;

ln pax per flightkt: média de passageiros transportados por voo;

ln load factorkt: taxa de ocupação;

In destinationskt: número de destinos;

ln fleet sizekt: tamanho médio da frota;

In fleet agekt: idade média da frota;

ln avg stage lengthkt: distância de voo média;

ln askkt: quantidade de assentos quilômetros disponíveis;

ln prop delaykt: proporção de atrasos de voo reportados;

ln prop airc failkt: proporção de falhas de aeronave reportadas;

ln caskkt: custo por assento disponível quilômetro ;

demand grw6t: crescimento da demanda nos 6 meses seguintes;

demand grw12t: crescimento da demanda nos 12 meses seguintes;

demand grw24t: crescimento da demanda nos 24 meses seguintes;

route grw6t: crescimento do número de rotas nos 6 meses seguintes;

route grw12t: crescimento do número de rotas nos 12 meses seguintes; 
route grw24t: crescimento do número de rotas nos 24 meses seguintes;

tendencykt: tendência de longo prazo da variável y;

tendency $\times$ hseakt: tendência de longo prazo interagida com dummy de alta estação;

tendency $\times$ prop delaykt: tendência de longo prazo interagida com a proporção de atrasos;

tendency $\times$ fuel cstkt: tendência de longo prazo interagida com o valor gasto com combustível;

$\beta_{0} \ldots \beta_{22}$ : parâmetros desconhecidos;

ukt: termo de erro composto (efeitos aleatórios);

0 raciocínio para o modelo apresentado na Equação (1) baseia-se em quatro vertentes principais que incluem fatores de operação, de custo, de demanda e tendências temporais, conforme apresentado na Figura 1.

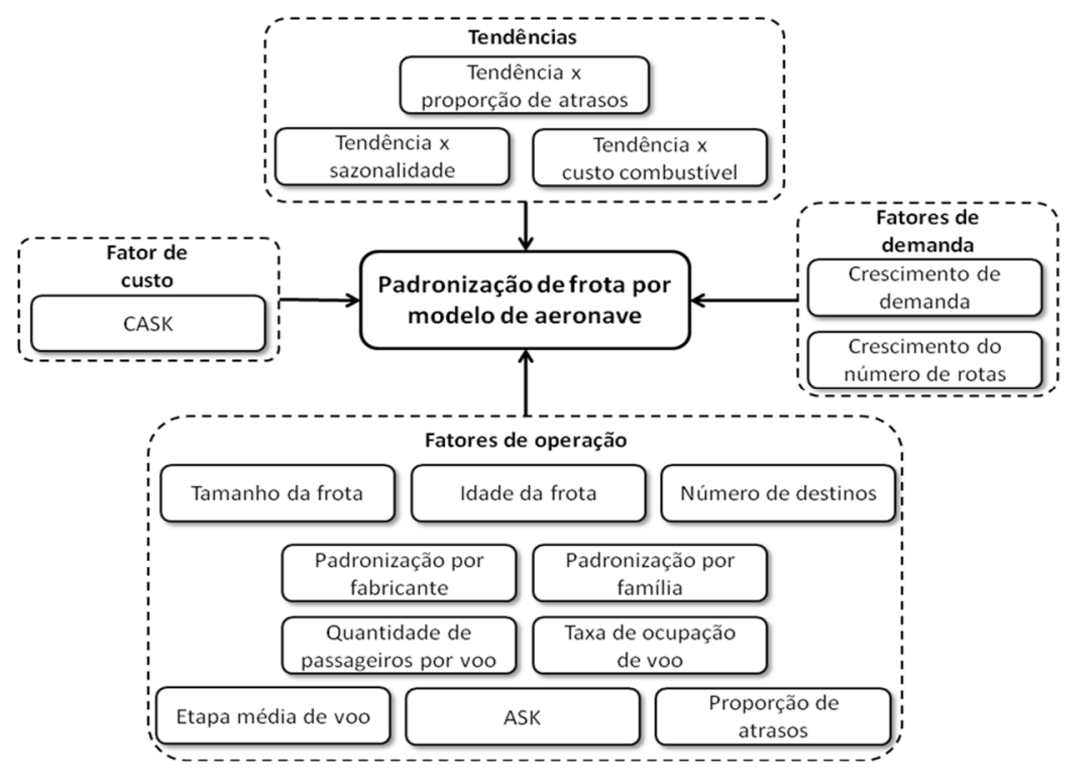

Figura 1: Modelo conceitual

Embora a discussão da relação entre comunalidade e custo operacional geralmente fique em torno dos efeitos da comunalidade sobre os custos, a aplicação de tais variáveis nesse modelo visa justamente identificar o efeito oposto. Ou seja, a influência dos mais diversos fatores na decisão de uma companhia em padronizar sua frota. Observa-se na Figura 1, por exemplo, diversas variáveis ligadas às questões operacionais, tais como idade de frota, etapa média voada, quantidade de assento-quilômetro disponível, entre outros.

Dos aspectos relacionados às operações de voo, vale ressaltar na Figura 1, o número de destinos e, consequentemente, se a empresa opera em nichos de mercado. De forma geral, presume-se que se a operação é feita em nichos de mercado, a padronização tende a prejudicar a operação, uma vez que a demanda é muito variável. Por outro lado, a operação majoritária em mercados de massa comumente apresenta pouca variação na demanda, o que pode ser benéfico à rentabilidade da empresa caso esta tenha uma frota padronizada por uma aeronave também adequada ao mercado em que opera. De forma similar, quanto maior a frota supõe-se que a empresa opere em diversos mercados com diferentes demandas, sendo possivelmente interessante para a mesma a presença de modelos com capacidades e autonomias distintas. 
Os fatores de demanda questionam, por sua vez, se a previsão de mudança significativa da demanda em curto prazo (6 meses, por exemplo), não poderia funcionar como um incentivo à aquisição de diferentes modelos de aeronaves que possam ser mais rapidamente incorporadas à frota para atender ao cenário de crescimento esperado. Tal ideia baseia-se no fato de que a compra de uma aeronave demanda tempo e é feita visando o longo prazo. Isso criaria uma desvantagem competitiva para a companhia, caso esta não esteja disposta a incorporar em sua frota modelos que tenham aquisição/entrega mais rápida do que o modelo de aeronave já operado. Paralelamente, a previsão de mudança significativa da demanda em prazo maior (24 meses), pode resultar em maior disponibilidade de tempo para se adequar às modificações do mercado, sem a necessidade de buscar por modelos alternativos de aeronaves.

A premissa para os fatores de custo baseia-se no questionamento se ainda hoje, mesmo já passado gerações de empresas low-cost e convergência de modelo de negócios, são ainda as companhias aéreas de baixo custo que mais preferem a padronização. Por fim, as variáveis de tendência temporal investigam justamente qual propensão da variável explicada, ou seja, da padronização por modelo. Tais variáveis possuem ainda interações com outros aspectos ligados ao mercado como um todo, como custo de combustível e idade de frota, tornando possível identificar se tais elementos possuem um efeito intensificador ou atenuador para a tendência de padronização de frota das companhias.

Tabela 2: Estatísticas descritivas do modelo dos determinantes da padronização de frota

\begin{tabular}{llllll}
\hline Variável & N. obs. & Média & Err. Padr. & Mín. & Máx. \\
\hline standard.: model & 385 & 0.54 & 0.17 & 0.30 & 1.00 \\
standard.: manufac & 385 & 0.92 & 0.15 & 0.50 & 1.00 \\
standard.: family & 385 & 0.86 & 0.16 & 0.50 & 1.00 \\
In pax per flight & 385 & 4.42 & 0.45 & 3.14 & 4.94 \\
In load factor & 385 & -0.55 & 0.34 & -1.58 & -0.08 \\
In destinations & 385 & 3.60 & 0.43 & 1.10 & 4.63 \\
In fleet size & 385 & 3.66 & 1.09 & 0.00 & 4.99 \\
In fleet age & 385 & 1.74 & 0.60 & -0.69 & 2.74 \\
In avg stage length & 385 & 6.71 & 0.15 & 6.36 & 7.02 \\
In ask & 385 & 20.96 & 0.95 & 16.80 & 22.14 \\
In prop delay & 385 & -1.52 & 0.44 & -2.82 & -0.45 \\
In prop airc fail & 385 & -5.12 & 1.20 & -9.62 & -2.54 \\
In cask & 385 & -1.48 & 0.38 & -2.99 & -0.31 \\
demand grw6 & 385 & 0.17 & 0.67 & -0.39 & 12.31 \\
demand grw12 & 385 & 0.34 & 1.02 & -0.33 & 18.53 \\
demand grw24 & 385 & 0.69 & 2.21 & -0.26 & 40.57 \\
route grw6 & 385 & 0.13 & 0.48 & -0.73 & 4.67 \\
route grw12 & 385 & 0.25 & 0.69 & -0.70 & 7.50 \\
route grw24 & 385 & 0.57 & 1.79 & -0.72 & 23.83 \\
tendency & 385 & 85.12 & 42.01 & 1.00 & 144.00 \\
tendency x hsea & 385 & 20.85 & 41.67 & 0.00 & 140.00 \\
tendency $x$ prop delay & 385 & 20.42 & 12.30 & 0.19 & 54.88 \\
tendency $x$ fuel cst & 385 & 246.23 & 190.80 & 1.13 & 782.57 \\
\hline
\end{tabular}

O modelo conceitual da Figura 1 serviu de referência para o desenvolvimento do modelo econométrico da Equação (1). No procedimento de estimação, construiu-se uma base de dados produzida a partir de diversas publicações e dados estatísticos liberados pela Agência Nacional de Aviação Civil (ANAC). A base utilizada possui informações do período de janeiro de 2002 até dezembro de 2013. No total, foram contabilizados dados de quatro companhias aéreas brasileiras (Azul, Gol, Avianca e Tam). 
No modelo da Equação (1), embora a métrica utilizada para efetuar o cálculo da padronização de frota considere os diversos modelos de aeronaves que as companhias utilizaram nesse período (Airbus A318, A319, A320, A321, A332, A333, Boeing 733, 737, 738, 752, 763, 773, Embraer E120, E170, E190, ATR42, ATR72 e Fokker 50 e 100), a base de dados é somente desagregada por companhia aérea. A justificativa para tal é de que a padronização de frota é calculada apenas por companhia, uma vez que, dentro de uma mesma empresa, o índice de padronização deve ser o mesmo para todos os modelos de aeronaves existentes. Por se tratar de um painel de dados, as informações sobre cada empresa são apresentadas em uma periodicidade mensal até o último período observado. Ao todo, são 385 observações e as estatísticas descritivas de cada variável estão apresentadas na Tabela 2.

\section{RESULTADOS}

A partir do modelo empírico proposto na Equação (1), e, considerando ainda que a variável explicada se constitui uma variável censurada com valores entre 0 e 1 , um modelo Tobit com efeitos aleatórios foi utilizado para a estimação dos coeficientes de cada variável. Os resultados do modelo são apresentados na Tabela 3.

Tabela 3: Resultados Estimados

\begin{tabular}{|c|c|c|c|c|c|}
\hline standard.: model & (1) & (2) & (3) & (4) & (5) \\
\hline standard.: manufac & 0.1112 & $0.1486^{*}$ & $0.4900 * * *$ & $0.6037 * * *$ & $0.6179 * * *$ \\
\hline standard.: family & $0.2965 * * *$ & $0.2999 * * *$ & $0.1961 * * *$ & $0.1723 * * *$ & $0.1834 * * *$ \\
\hline In pax per flight & $0.9826 * * *$ & $1.0272 * * *$ & $0.4461 * * *$ & $0.4339 * * *$ & $0.4125 * * *$ \\
\hline In load factor & $-0.7608 * * *$ & $-0.7891 * * *$ & $-0.3920 * * *$ & $-0.3929 * * *$ & $-0.3654 * * *$ \\
\hline In destinations & $-0.2062 * * *$ & $-0.1545 * * *$ & -0.0510 & -0.0025 & $-0.1252 * * *$ \\
\hline In fleet size & $-0.3365 * * *$ & $-0.3524 * * *$ & $-0.3181 * * *$ & $-0.3263 * * *$ & $-0.2882 * * *$ \\
\hline In fleet age & $-0.0637 * * *$ & $-0.0483 * *$ & $-0.0963 * * *$ & $-0.0820 * * *$ & \\
\hline In avg stage length & $-0.2719 * * *$ & $-0.2791 * * *$ & $-0.3878 * * *$ & $-0.3484 * * *$ & $-0.5296 * * *$ \\
\hline In ask & $0.3023 * * *$ & $0.3334 * * *$ & $0.1043^{* * *}$ & $0.1038^{* * *}$ & $0.1304 * * *$ \\
\hline In prop delay & $-0.1348 * * *$ & $-0.1201 * * *$ & $-0.0273^{*}$ & -0.0095 & -0.0091 \\
\hline In prop airc fail & $1.4578^{* *}$ & $1.3701^{* *}$ & $0.0288 * * *$ & $0.0286 * * *$ & $0.0286 * * *$ \\
\hline In cask & -0.0022 & 0.0102 & 0.0117 & 0.0205 & 0.0208 \\
\hline demand grw6 & & -0.0200 & & $-0.0642 * * *$ & $-0.0755^{* * *}$ \\
\hline demand grw12 & & 0.0371 & & -0.0032 & 0.0025 \\
\hline demand grw24 & & $0.0551 * * *$ & & $0.0611 * * *$ & $0.0690 * * *$ \\
\hline route grw6 & & $-0.0170 *$ & & -0.0082 & -0.0086 \\
\hline route grw12 & & $-0.0222 * *$ & & $-0.0197^{* *}$ & $-0.0219 * *$ \\
\hline route grw24 & & 0.0004 & & -0.0025 & -0.0081 \\
\hline tendency & & & $0.0045 * * *$ & $0.0047^{* * *}$ & $0.0044 * * *$ \\
\hline tendency $\times$ hsea & & & -0.0000 & -0.0000 & 0.0000 \\
\hline tendency $\times$ prop delay & & & $0.0015^{*}$ & 0.0006 & 0.0007 \\
\hline tendency $\times$ fuel cst & & & $-0.0004 * * *$ & $-0.0004 * * *$ & $-0.0003 * * *$ \\
\hline efeitos aleatórios & $\operatorname{sim}$ & $\operatorname{sim}$ & $\operatorname{sim}$ & $\operatorname{sim}$ & $\operatorname{sim}$ \\
\hline R-quadrado ajustado & 0.7823 & 0.7888 & 0.8115 & 0.8197 & 0.7380 \\
\hline Estatística RMSE & 0.0784 & 0.0773 & 0.0720 & 0.0704 & 0.0849 \\
\hline Estatística F & 40.697 & 59.685 & 39.339 & 58.968 & 26.806 \\
\hline № de observações & 385 & 385 & 385 & 385 & 385 \\
\hline
\end{tabular}

Notas: Resultados produzidos por um modelo Tobit; R-quadrado ajustado, estatísticas RMSE e F foram produzidas por um modelo de mínimos quadrados ordinários consistente a heteroscedasticidade e autocorrelação (OLS-HAC) de especificação idêntica; representações do P-valor: ***p<0.01, ${ }^{* *} p<0.05,{ }^{*} p<0.10$; Coluna (1): modelo apenas com variáveis operacionais e de custo; Coluna (2): modelo com variáveis operacionais, de custo e de demanda; Coluna (3): modelo com variáveis operacionais, de custo e de tendência; Coluna (4): modelo empírico principal com todas as variáveis; Coluna (5): modelo com variável faltante para teste de robustez do modelo principal. 
Conforme apresenta a Tabela 3, os resultados foram organizados de forma a apresentar ao leitor a evolução do modelo empírico proposto na Equação (1), trazendo ainda a variação dos resultados de cada variável à medida que novos fatores explicativos são adicionados. A Coluna (1), por exemplo, apenas apresenta as variáveis dos fatores operacionais e de custo.

Observando os resultados da Tabela 3, nota-se que, entre as variáveis de padronização (standard.: manufac/family), apenas a padronização de família apresentou significância estatística elevada e correlação positiva com a padronização em nível de modelo (standard.: model). Embora também funcionem como variáveis de controle, a expectativa para ambas as variáveis era de correlação positiva, uma vez que existe a premissa de que se a companhia aérea já possui algum tipo de padronização, o aprofundamento desta em um maior grau é mais provável do que em condições contrárias. Note que aspectos como negociação e poder de barganha são fundamentais na aquisição e arrendamento de novas aeronaves. Uma vez que esses fatores não podem ser observados, ambas as variáveis de padronização são consideradas como possivelmente endógenas e são passíveis de instrumentação.

A quantidade de passageiros por voo (ln pax per flight) apresentou-se positivamente correlacionada com a padronização de modelo, ao passo que a taxa de aproveitamento de voo (ln load factor) mostrou-se negativamente correlacionada. A primeira variável funciona ainda como uma proxy para tamanho médio de aeronave, sugerindo que, com mais passageiros por voo, aeronaves maiores operam mais eficientemente em mercados de alta densidade, os quais são também os mais maduros. Pode-se concluir que esses mercados não sofrem tantas variações na demanda de forma a ser vantajoso à companhia aérea possuir modelos de aeronaves diversos com capacidades diferentes. Por outro lado, a variável de aproveitamento de voo baseia-se na ideia de que voos regionais e em mercados de nicho possuem uma probabilidade de elevada taxa de ocupação maior do que em mercados de massa, uma vez que nesses mercados há poucos voos e poucas empresas operando. Ressalta-se que, embora haja baixa concorrência, a demanda também é bastante volátil, fazendo com que seja interessante à empresa aérea possuir aeronaves com capacidades diferentes para acomodar oscilações.

Ainda na Coluna (1), nota-se que a variável de número de destinos servidos (ln destinations) mostrou-se possuindo efeito negativo. Espera-se que quanto maior a malha, maior é a necessidade de adequar as aeronaves às características de mercado e distâncias de cada rota. Da mesma forma, quanto maior e mais velha a frota ( In fleet size e In fleet age), menor a padronização em nível de modelo. Sugerimos que os novos modelos de aeronaves, que se caracterizam por melhorias e avanços tecnológicos, são, por vezes, preferíveis à companhia aérea do que manter um modelo de geração anterior e mais velho.

A ideia que envolve a interpretação de resultados da variável idade de frota merece, assim, destaque. Conforme novos modelos de aeronaves mais avançados e econômicos são lançados, há um maior interesse das companhias aéreas em renovar a sua frota mesmo se isto significar uma redução na sua padronização de modelo de aeronave. Em outras palavras, pode-se dizer que manter uma aeronave com mais avanços tecnológicos pode ser preferível a manter a padronização de aeronaves mais velhas de um modelo anterior. Adicionalmente, pode-se supor que no longo prazo, a renovação da frota por modelos de aeronaves de gerações mais recentes pode ser duplamente benéfica para a companhia aérea. Se, por um lado, a empresa reduz a padronização para adquirir aeronaves mais econômicas e isso garante economia de combustível, por outro, e considerando o longo prazo, conforme a frota for renovada, a companhia terá aeronaves mais modernas e poderá voltar a elevar a sua padronização com esses novos modelos. 
Assim, se adequadamente gerenciada, a renovação da frota de uma companhia aérea pode trazer eficiência tanto no consumo de combustível, quanto nos ganhos operacionais advindos da comunalidade, bastando que a empresa se mantenha fiel ao novo modelo de aeronave escolhido. A implicação de tal gerenciamento é a elevação da eficiência da operação aérea da companhia e consequentemente da sua competitividade no mercado.

A variável de distância média voada (ln avg stage length) apresentou correlação negativa e significante, indicando que, conforme há um crescimento na distância voada, há também uma diminuição na padronização de modelo existente na frota. A hipótese para tal é de que, à medida que os voos se tornam mais longos, a amplitude e variação dos mercados atendidos também aumentam, fazendo com que aeronaves de autonomia e portes diferentes possam ser interessantes ao seu operador. Já a quantidade de assento-quilômetro disponível (ln ask) apresentou correlação positiva, sugerindo que companhias que possuam um elevado valor nesse índice são mais propensas a padronizar mais.

As últimas variáveis operacionais do modelo são as de proporção de atrasos (In prop delay) e proporção de falha de aeronaves (In prop airc fail). Enquanto a primeira apresentou correlação positiva, a última apresentou correlação negativa. Nota-se, através dos resultados, que companhias com menores índices de atrasos possuiriam também maior padronização de frota. Ao mesmo tempo, nota-se também que companhias com maiores índices de falha de aeronaves possuiriam também maior propensão a padronizar suas frotas. A premissa para tal circunstância é de que a padronização de frota seria vista como uma possível solução às falhas das aeronaves. Observa-se, por exemplo, que frotas padronizadas possuem os benefícios da comunalidade. Ou seja, tornam possível o compartilhamento de peças e até mesmo de se efetuar a troca de aeronaves na escala de voo da companhia sem grandes consequências no planejamento de voo da empresa. Portanto, pode-se concluir que a padronização traz vantagens operacionais às empresas com índices de falha elevados. Dessa forma, pode-se afirmar que a padronização de frota é vista justamente como consequência de um elevado índice de falha, e não mais como uma causa para um baixo índice.

Por fim, a Coluna (1) apresenta também a variável de custo (In cask), a qual se mostrou, no modelo, como estatisticamente insignificante. A característica de frota única e com elevada comunalidade é, como exposto na literatura, geralmente associada a companhias de baixo custo. Por essa razão, partiu-se do pressuposto de que a padronização reduziria os custos operacionais e que companhias de menores custos possuiriam tendência a padronizar mais.

Apesar da adição das variáveis de demanda na Coluna (2) da Tabela 3, os resultados das variáveis operacionais e de custo não sofreram alteração, salvo para padronização de fabricante (standard.: manufac), o qual apresentou significância estatística baixa. Conforme discutido anteriormente, a hipótese para as variáveis de crescimento de demanda era de que, em curto prazo, companhias aéreas poderiam se sentir motivadas a reduzir a padronização de frota em prol do recebimento mais rápido de novas aeronaves. 0 pressuposto também cogitava a ideia de que o oposto ocorreria quando o crescimento da demanda era para longo prazo. Nota-se, entretanto, que apenas a variável de longo prazo (demand grw24) apresentou significância estatística, indicando não existir efeito nos prazos de 6 e 12 meses (demand grw6/grw12). Uma vez que a premissa para o crescimento do número de rotas é similar ao crescimento da demanda, os sinais esperados para os resultados também não sofreram tanta variação. Entretanto, nota-se que dessa vez apenas as variáveis nos prazos de 6 e 12 meses (route grw6 / grw12) 
apresentaram correlação significante e negativa, ao passo que a variável de 24 meses (route grw24) mostrou-se estatisticamente insignificante.

Os resultados das variáveis operacionais na Coluna (3) não sofreram grandes alterações. A exceção se dá no número de destinos (In destinations) e padronização de fabricante (standard.: manufac). Enquanto a primeira perdeu sua significância estatística, a segunda passou a ter correlação positiva e significante com o regressando, corroborando a explicação dada para a mesma. Adicionalmente, vale ressaltar os resultados obtidos com as variáveis de tendência temporal. A variável tendência (tendency) indicou que há uma predisposição para um aumento na padronização de frota observada nas companhias, contrariando os resultados de Kilpi (2007) de que a padronização de frota estaria em decréscimo.

Nota-se que, quando interagida com custo de combustível (tendency $\times$ fuel cst) a tendência de padronização é atenuada, enquanto que nenhum efeito é observado na interação com proporção de atrasos (tendency $\times$ prop delay) e períodos de alta estação (tendency $\times$ hsea). Desses resultados, estimativa mais significante diz respeito à variável tendency $\times$ fuel cst e indica que 0 custo com querosene de aviação pode ser um fator inibidor da tendência à padronização das companhias aéreas. Por outro lado, interpreta-se que, com o aumento de custos, as empresas buscam trocar aeronaves de sua frota por modelos mais eficientes e que apresentem maior economia de combustível, como os modelos mais avançados tecnologicamente.

Pode-se dizer que o preço do combustível é um fator considerado para a tomada de decisão sobre a padronização de frota. Entretanto, tal custo funciona apenas como um fator atenuador e não reverte a tendência primária da companhia em padronizar. Em outras palavras, momentos de elevação do preço do combustível podem até ser um incentivo à aquisição de aeronaves mais eficientes e consequente redução da padronização, mas ainda assim tal elevação no preço não é suficiente para modificar a tendência de padronização da empresa estabelecida durante um planejamento de longo prazo.

Os resultados referentes ao efeito do preço do querosene de aviação na tendência à padronização podem, dessa forma, ser indicativos de que as empresas respondem a choques de custos com combustível de maneira eficiente, e poderiam assim intensificar a inovação tecnológica do setor em um cenário, por exemplo, de maiores custos com medidas econômicas ambientais impostas sobre o querosene de aviação. Uma política ambiental mais ativa tem sido fortemente recomendada pela Organização da Aviação Civil Internacional, OACI, para a próxima década.

Os resultados obtidos com o modelo completo podem ser visualizados na Coluna (4) da Tabela 3. Notam-se variações pontuais quando os resultados são comparados com os obtidos nas Colunas (1)-(3). Das variáveis operacionais, apenas número de destinos (In destinations) e proporção de atrasos (ln prop delay) perderam a significância estatística. Dentre as variáveis de demanda, o crescimento da demanda em 6 meses (demand grw6) obteve a correlação negativa esperada, fortalecendo a hipótese de que as companhias priorizariam uma redução na padronização em prol de obter aeronaves mais rapidamente. De forma contrária, a variável de crescimento do número de rotas em 6 meses (route grw6) perdeu a significância observada na Coluna (2). As variáveis de tendência não sofreram variações significativas.

Por fim, a Coluna (5) representa um dos diversos testes de robustez que foram feitos com o modelo principal, o qual é apresentado na coluna anterior. Observa-se, no exemplo citado, que a retirada da variável de idade de frota (ln fleet age) não trouxe ao modelo empírico muitas variações nos resultados obtidos, mostrando que o modelo proposto é robusto o suficiente para 
não sofrer grandes variações mesmo após perturbações terem sido feitas em sua especificação principal.

\section{CONSIDERAÇÕES FINAIS}

0 presente trabalho investigou os determinantes da tomada de decisão quanto à padronização da frota por companhias aéreas brasileiras. Utilizou-se um modelo econométrico de índice de padronização, estimado com dados do setor de transporte aéreo entre 2002 e 2013 . Os principais resultados que podem ser destacados são relativos às variáveis de idade de frota, custo com combustível e tendência à padronização.

A relação negativa entre idade de frota e padronização de modelo de aeronave apontada pelo modelo sugere uma preferência das companhias aéreas em renovar a sua frota, do que manter a padronização de aeronaves mais antigas e possivelmente de uma geração anterior. A busca por novas tecnologias mais eficientes é visível quando há uma redução da padronização conforme a frota envelhece, assim como apresentam os resultados. Aeronaves mais modernas e eficientes não somente têm o potencial de reduzir o consumo de combustível e o custo da empresa, como também implicam em reduções nas emissões de CO2. Ressalta-se, assim, que a redução das emissões de carbono é aspecto que pode ser incentivado por políticas públicas que estimulem a aquisição de aeronaves mais eficientes por parte das companhias aéreas, ou que eventualmente tragam ônus às empresas com frotas compostas de aeronaves menos econômicas.

Similarmente, os resultados quanto à tendência de aumento da padronização denotam um interesse das companhias aéreas em reduzir seus custos operacionais por meio do aumento dos benefícios decorrentes da comunalidade. Por outro lado, o preço do combustível é um fator que pesa na intensidade com que a padronização da frota da companhia aérea ocorre ao longo do tempo, dado que o modelo estimado sugere que, em momentos de elevação dos custos, o interesse por tecnologias novas e mais eficientes sobressai.

0 trabalho possui um conjunto de limitações, dentre as quais se destaca o procedimento de estimação utilizado. Ressalta-se que o modelo pode sofrer de problemas de endogeneidade dos regressores, como por exemplo, nas variáveis de custo e de padronização de frota em nível de fabricante e família. Paralelamente, sugere-se a inserção de novas variáveis de experimentação e a verificação de seus efeitos, tais como quantidade de aeroportos "hub", participação em alianças globais, fila de pedidos, entregas de novas aeronaves e o efeito da concorrência. Por fim, sugere-se uma investigação mais abrangente, sobre os efeitos da padronização na eficiência operacional e financeira das empresas em estudos futuros.

\section{AGRADECIMENTOS}

Coordenação de Aperfeiçoamento de Pessoal de Nível Superior (Capes) - Programa de Demanda Social (DS), Fundação de Amparo à Pesquisa do Estado de São Paulo (FAPESP) - Auxílio Pesquisa n. 2015/19444-1; Conselho Nacional de Desenvolvimento Científico e Tecnológico (CNPq). Os autores gostariam de agradecer os comentários de Renan Oliveira, Humberto Bettini, Cláudio Jorge P. Alves, Rogéria Arantes, Mariana Castro e dos participantes e avaliadores da ANPET. Todos os eventuais erros e omissões são de nossa autoria.

\section{REFERÊNCIAS}

ABEAR (2017). Panorama 2016: o setor aéreo em dados e análises. Associação Brasileira de Empresas Aéreas, Brasília. ANAC (2015) Anuário do transporte aéreo 2014. Agência Nacional de Aviação Civil, Brasília.

Borges Pan, A. G. e R. A. E. Santo Jr (2004) Developing a fleet standardization index for airline pricing. Journal of Air Transportation, v. 9, n. 2, p. 97-110.

Brüggen, A. e L. Klose (2010) How fleet commonality influences low-cost airline operating performance: Empirical evidence. Journal of Air Transport Management, v. 16, n. 6, p. 299-303. DOI: 10.1016/j.jairtraman.2010.02.006. 
Flightglobal (2011) Commonality, performance tipped Southwest to 737 Max. Washington, DC, USA.

Kilpi, J. (2007) Fleet composition of commercial jet aircraft 1952-2005: Developments in uniformity and scale. Journal of Air Transport Management, v. 13, n. 2, p. 81-89. DOI: 10.1016/j.jairtraman.2006.10.008

Seristö, H. e A. P. Vepsälainen (1997) Airline cost drivers: cost implications of fleet, routes, and personnel policies. Journal of Air Transport Management, v. 3, n. 1, p. 11-22. D0I: 10.1016/S0969-6997(97)82788-3

Zou, L; C. Yu e M. Dresner (2015) Fleet Standardisation and Airline Performance. Journal of Transport Economics and Policy, v. 49, n. 1, p. 149-166.

Zuidberg, J. (2014) Identifying airline cost economies: An econometric analysis of the factors affecting aircraft operating costs. Journal of Air Transport Management, v. 40, p. 86-95. DOI: 10.1016/j.jairtraman.2014.06.007 